\title{
POTENCIAL PRODUTIVO DE PENNISETUM SPP. SOB NÍVEIS DE NITROGÊNIO NA ZONA DA MATA DE PERNAMBUCO\#
}

\author{
YIELD POTENTIAL OF PENNISETUM SPP. UNDER NITROGEN LEVELS IN THE \\ FOREST ZONE OF PERNAMBUCO
}

\author{
Cavalcante, M. ${ }^{1 *}$; Lira, M.A. ${ }^{2}$; Santos, M.V.F. ${ }^{3}$; Santoro, K.R. ${ }^{4}$; Ferreira, R.L.C. ${ }^{5}$ \\ e Leão Neto, J.M.C. ${ }^{1}$
}

\begin{abstract}
${ }^{1}$ Programa de Doutorado Integrado em Zootecnia.UFRPE. Recife/PE. Brasil. *marcelo.agronomia@gmail.com 2Instituto Agronômico de Pernambuco (IPA). Recife/PE. Brasil.

${ }^{3}$ Departamento de Zootecnia. UFRPE. Recife/PE. Brasil.

${ }^{4}$ Departamento de Biotecnologia e Melhoramento Animal. UFRPE/UAG. Garanhuns/PE. Brasil.

${ }^{5}$ Departamento de Ciências Florestais. UFRPE. Recife/PE. Brasil.
\end{abstract}

\section{PalaVRas ChaVE ADICIONAIS}

Adaptabilidade. Estabilidade. Pennisetum glaucum. Pennisetum purpureum.

\section{RESUMO}

Avaliou-se o potencial produtivo, a adaptabilidade e a estabilidade de 16 genótipos de Pennisetum spp. sob a influência de quatro níveis de nitrogênio, durante seis ciclos de avaliações. O experimento foi instalado na Estação Experimental do Instituto Agronômico de Pernambuco/ltambé, no esquema de parcelas subdivididas, com quatro níveis de nitrogênio (N) (controle, 30, 60 e 90 kg ha $^{-1}$ corte $^{-1}$ ) e 16 genótipos (G) de Pennisetumspp. (10 novos híbridos interespecíficos, um híbrido interespecífico cultivado e cinco cultivares de capim-elefante), em três blocos. Os ciclos (Cl) compreenderam avaliações em 2010 (21/04, 19/ 07 e 28/09) e em 2011 (06/01, 07/04 e 03/08). A massa de forragem (MF), o comprimento da folha (CF), a largura da folha (LF) e o comprimento do entrenó (CE) sofreram influência da interação tripla ( $\mathrm{N} \times \mathrm{G} \times \mathrm{Cl}$ ). O novo híbrido, IPA-7 (Pioneiro $x$ IPA Bulk-1) não foi influenciado pela interação, apresentando adaptabilidade geral $\left(\beta_{1}=1\right)$ e alta estabilidade $\left(\sigma^{2}=0\right)$ para a MF, com valores médios de $0,88 \mathrm{~kg} \mathrm{MS} \mathrm{touceira}^{-1}$ corte $^{-1}, 76,24 \mathrm{~cm}$ e $78,79 \mathrm{~mm}$, para a MF, CF e CE, respectivamente. Este híbrido poderá ser selecionado para a próxima fase do Programa de Melhoramento de Pennisetum spp.

\#Trabalho realizado através do convênio IPA/UFRPE.

\section{Additional KEYWORdS}

Adaptability. Pennisetum glaucum. Pennisetum purpureum. Stability.

\section{SUMMARY}

The productive potential, adaptability and stability were evaluated in 16 Pennisetum spp. genotypes under the influence of four nitrogen levels in six evaluations cycles. The experiment was carried out in 2009, at the Itambé Experimental Station of Pernambuco, Agricultural Research Institute-IPA, Northeast Brazil, in split plots scheme, with four nitrogen $(\mathrm{N})$ levels (control, 30, 60 and $90 \mathrm{~kg} \mathrm{ha}^{-1} \mathrm{cut}^{-1}$ ) and 16 Pennisetum spp. genotypes (G) (10 new interspecific hybrids, one cultivated interspecific hybrid and five elephant grass varieties), in three blocks. The cycles ( $\mathrm{Cl}$ ) comprised evaluations in $2010(04 / 21,07 / 19$ and 09/28) and 2011 (01/06, 04/07 and 08/03). The forage mass (MF), the leaf length (CF), the leaf width (LF) and the internode length (CE) were influenced by triple interaction ( $\mathrm{N} \times \mathrm{G} \times \mathrm{Cl}$ ). The new hybrid, IPA-7 (Pioneiro $x$ IPA Bulk-1), was not influenced by the interaction, presenting high adaptability $\left(\beta_{1}=1\right)$ and high stability $\left(\sigma^{2}{ }_{\mathrm{di}}=0\right)$ for the MF, reaching average of $0.88 \mathrm{~kg} \mathrm{DM}$ shoot $^{-1} \mathrm{cut}^{-1}, 76.24 \mathrm{~cm}$ and $78.79 \mathrm{~mm}$ for MF, CF and CE, respectively. This hybrid can be selected for the next phase of the Breeding Program of Pennisetum spp.

\section{INTRODUÇÃO}

O capim-elefante (Pennisetum purpu- 


\section{CAVALCANTE, LIRA, SANTOS, SANTORO, FERREIRA E LEÃO NETO}

reum Schum.) é uma das mais importantes forrageiras cultivadas, devido ao seu elevado potencial de produção de matéria seca, palatabilidade, vigor e persistência, além de ser adaptado a quase todas as regiões tropicais e subtropicais do mundo (Ferreira e Pereira, 2005). Euma espécie que pode ser cultivada para ser manejada sob as formas de capineira, consórcio e pastejo (Lira et al., 2010; Carneiro et al., 2006). Algumas de suas características (qualidade forrageira, tolerância à seca e às doenças) podem ser melhoradas quando genes do milheto $(P$. glaucum L.R. Brown) são incorporados ao germoplasma do capim-elefante através de hibridações (Jauhar e Hanna, 1998).

A obtenção de novos genótipos, seja por hibridações intra ou interespecíficas, resulta da demanda crescente pela busca por plantas mais competitivas e adaptadas a diferentes condições edafoclimáticas. De acordo com Lira et al. (1996), a deficiência nutricional do solo constitui um dos problemas determinantes no estabelecimento e na manutenção das pastagens melhoradas. Dos nutrientes, o nitrogênio, por ser constituinte do DNA, dos aminoácidos livres e protéicos, além de participar das moléculas de clorofila, é um dos elementos mais limitante na produção de forragem nas condições tropicais. Segundo Primavesi et al. (2004), o nitrogênio está entre os fatores mais importantes a determinar a produção por área, além de promover incrementos na produção de matéria seca das forrageiras com alto potencial de produção, como o capim-elefante.

A recomendação de nitrogênio para o capim-elefante no Estado de Pernambuco, espaçado a 1,0 m entre linhas, com produtividade média de 10,0 Mg MS ha- $\mathrm{ano}^{-1}$, é de 40,0 $\mathrm{kg} \mathrm{ha}^{-1}$ aplicados aos 15 dias após o plantio e de $80,0 \mathrm{~kg} \mathrm{ha}^{-1}$ aplicados após cada corte, dependendo das condições de umidade do solo (Santos et al., 2008). Desse modo, torna-se necessário gerar genótipos de Pennisetum spp. que apresentem incrementos produtivos sob baixos níveis de $\mathrm{N}$, considerando os custos com este insumo e com mão de obra. Logo, o estudo da interação genótipo x nitrogênio permitirá a identificação e a seleção de genótipos promissores.

O estudo da adaptabilidade e da estabilidade também consiste em uma ferramenta que permite ao pesquisador obter informações pormenorizadas sobre o comportamento de cada genótipo frente às variações ambientais, tornando-se possível a identificação daqueles que tenham comportamento previsível e que sejam responsivos às variações ambientais, em condições específicas ou amplas (Cruz e Regazzi, 2001).

Desse modo, objetivou-se avaliar o potencial produtivo, a adaptabilidade e a estabilidade de 16 genótipos de Pennisetum spp. sob quatro níveis de $\mathrm{N}$, durante seis ciclos de avaliação.

\section{MATERIALE MÉTODOS}

O experimento foi instalado em 2009 na Estação Experimental do Instituto Agronômico de Pernambuco, localizada no município de Itambé. A área está situada sob as coordenadas $7^{\circ} 25^{\prime} \mathrm{S}$ e $35^{\circ} 06^{\prime} \mathrm{W}$, na microrregião fisiográfica da Mata Seca de Pernambuco, a $190 \mathrm{~m}$ de altitude. O solo da área foi classificado como Argissolo Vermelho-Amarelo, distrófico, com horizonte A proeminente de textura média/argilosa, fase floresta tropical subcaducifólia (Beltrão et al., 2005). A precipitação pluvial total no primeiro e no segundo ano foi de 846,6 e de $1816,8 \mathrm{~mm}$ (até agosto), respectivamente. A média histórica, neste mesmo período, foi de 1359,0 e de 1216,0 mm (figura 1).

Foram avaliados 16 genótipos de Pennisetum spp., dos quais 10 foram novos híbridos interespecíficos, gerados a partir do cruzamento entre o cultivar de milheto IPA Bulk-1 (progenitor feminino) com quatro cultivares de capim-elefante Pioneiro (híbridos IPA-1, IPA-7, IPA-8), Elefante B (híbridos IPA-A2, IPA-A4, IPA-A5), IRI 381 (IPA-B1, IPA-B3), Taiwan A-146 (híbridos 


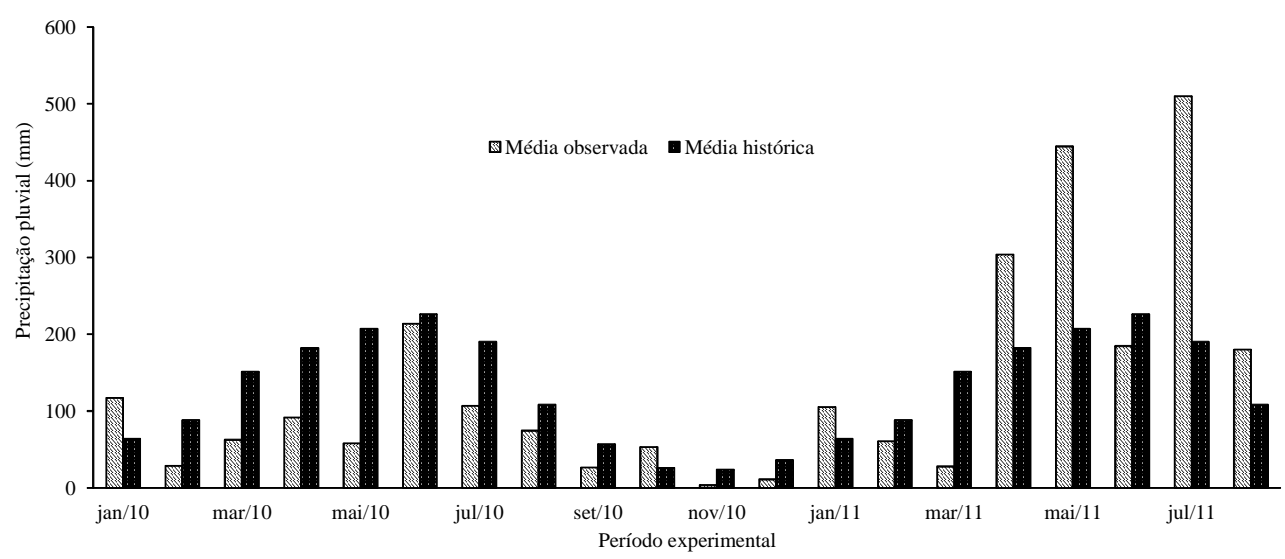

Figura 1. Precipitação pluvial $(\mathrm{mm})$ de Itambé durante o período experimental. (Rainfall (mm) of Itambé during the experimental period).

IPA-C8, IPA-C9), além do cultivar de capimelefante Mineirão e de um híbrido interespecífico desenvolvido e cultivado pelo IPA, o HV 241 (Elefante B x milheto 23A).

Os progenitores foram escolhidos a partir de características desejáveis: o cultivar IPA Bulk-1 foi escolhido por apresentar tolerância a solos de baixa fertilidade, ser uma das variedades de milheto disponíveis de maior adaptação ao Semiárido pernambucano e florescer com menos de 52 dias após o plantio (Lira, 1982). O cultivar Pioneiro, por apresentar elevado potencial produtivo, além de ser tolerante ao pastejo (Pereira et al., 1997). O cultivar Elefante B, por ser o clone mais antigo em cultivo no Brasil, além de ter apresentado nos testes preliminares realizados pelo IPA elevado número de perfilhos basilares e axilares. $\mathrm{O}$ cultivar IRI 381, por exibir grande adaptação à Zona da Mata e ao Agreste pernambucano, além da elevada produtividade de forragem (Freitas et al., 2004). O cultivar Taiwan A146, por ter exibido bons híbridos de porte baixo em cruzamentos já realizados pelo Instituto.

O experimento foi instalado em parcelas de 6,0 × 6,0 m no delineamento em blocos ao acaso com três blocos, sob o esquema de parcelas subdivididas, considerando as parcelas principais, níveis de $\mathrm{N}$ (controle, 30, 60 e $90 \mathrm{~kg} \mathrm{ha}^{-1}$ corte $^{-1}$, ureia) e as subparcelas, 16 genótipos de Pennisetum spp. A unidade experimental foi composta por uma touceira, devido à limitada disponibilidade de colmos-semente na ocasião da instalação do experimento. Em cada parcela principal foi feita uma bordadura com o cultivar IRI 381.

A análise química do solo na camada de 0,0 a $0,20 \mathrm{~m}$ apresentou as seguintes características: $\mathrm{pH}\left(\mathrm{H}_{2} \mathrm{O}\right): 4,9 ; \mathrm{P}: 10,0 \mathrm{mg} \mathrm{dm}^{-3}$; $\mathrm{Ca}$, $\mathrm{Mg}, \mathrm{K}, \mathrm{Al}$ e H: 0,66; 0,23; 0,07; 1,3 e 4,96 $\mathrm{cmol} \mathrm{dm}^{-3}$, respectivamente. Foram aplicadas 5,0 $\mathrm{Mg} \mathrm{ha}^{-1}$ de calcário dolomítico $[\mathrm{PRNT}=75,6 \%$; saturação de bases desejada $\left(\mathrm{V}_{2}\right)=65 \%$ ], aos 60 dias antes do plantio. A semeadura foi realizada entre os dias 05 e 09 de maio de 2009, no espaçamento de 2,0 x 1,0 $\mathrm{m}\left(2,0 \mathrm{~m}^{2}\right.$ touceira $\left.{ }^{-1}\right)$. Foram realizados replantios, principalmente dos novos híbridos, devido a dificuldade de estabelecimento desses genótipos, o que resultou em plantas com diferentes idades ontogênicas no mesmo tratamento. Aos 60 dias após o plantio foram realizadas as adubações fosfatada (44 kg P ha-1; superfosfato simples) e potássica ( $66 \mathrm{~kg} \mathrm{~K} \mathrm{ha}^{-1}$; cloreto de 


\section{CAVALCANTE, LIRA, SANTOS, SANTORO, FERREIRA E LEÃO NETO}

potássio). No dia 27 de janeiro de 2010 foi realizado um corte de uniformização rente ao solo em todos os genótipos, em seguida, aplicados os tratamentos nitrogenados. Todos os adubos foram incorporados ao solo com o auxílio de uma enxada.

Foram realizadas avaliações das variáveis massa seca de forragem (folha + colmo, $\mathrm{kg}$ touceira $^{-1}$, altura da planta $(\mathrm{m})$, comprimento da folha $(\mathrm{cm})$, largura da folha $(\mathrm{mm})$, diâmetro do colmo ( $\mathrm{mm}$ ) e comprimento do entrenó (mm) nos 16 genótipos de Pennisetum spp. em seis ciclos (CI) de avaliação: 1(21/04/2010), 2(19/07/2010),3(28/09/2010), $4(06 / 01 / 2011), 5(07 / 04 / 2011)$ e $6(03 / 08 /$ 2011). Em cada avaliação após o corte foram aplicados os tratamentos nitrogenados, juntamente com a adubação de manutenção de $66 \mathrm{~kg} \mathrm{~K} \mathrm{ha}^{-1}$ com cloreto de potássio.

A forragem cortada rente ao solo foi pesada no campo e uma fração da touceira (três perfilhos) foi levada ao laboratório para secagem em estufa de ventilação forçada, a $65^{\circ} \mathrm{C}$ por $72 \mathrm{~h}$, para posterior determinação da massa seca de forragem $\left(\mathrm{kg} \mathrm{MS}\right.$ touceira ${ }^{-1}$ corte $\left.^{-1}\right)$. A altura da planta foi obtida com o auxílio de uma trena, a partir da base do perfilho mais desenvolvido até a inflexão da folha mais alta. O comprimento e a largura da folha foram mensurados na primeira folha completamente expandida (aquela que apresentou a lígula completamente exposta), sendo as medidas obtidas com uma trena e com um paquímetro, respectivamente. A largura foi mensurada na região mediana da folha. Tanto o diâmetro do colmo quanto o comprimento do entrenó foram mensurados com o auxílio de um paquímetro no segundo entrenó a partir do solo (média de três perfilhos touceira ${ }^{-1}$ ).

Os dados foram submetidos a análise de medidas repetidas no tempo, utilizando modelos mistos pelo procedimento PROC MIXED (SAS Institute Inc., 2008). Avaliações preliminares indicaram a matriz componente de variância (VC), pelo menor valor no critério de Akaike (AIC), aquela que melhor se ajustou ao conjunto de dados de todas as variáveis. As médias foram obtidas pelo ajuste dos efeitos fixos por meio do comando LSMEANS do SAS. Calculou-se parâmetros de adaptabilidade (média geral, $\beta_{0}$; coeficiente de regressão linear, $\beta_{1}$ ) e de estabilidade (soma dos desvios absolutos da regressão, $\sigma_{\text {di }}^{2}$ ) para a massa de forragem por ser a principal variável avaliada. O método utilizado foi o de Eberhart e Russell, descrito por Cruz e Regazzi (2001). Considerando o número de genótipos avaliados, foi empregado o método de otimização de Tocher, tendo-se como medida de dissimilaridade a distância euclidiana, visando agrupar genótipos com alta similaridade genética para cada variável (Cruz, 2006). Nas interações, empregou-se regressão polinomial em nível de grupos de similaridade genética. Estas análises tiveram auxílio do software Genes.

\section{RESULTADOSEDISCUSSÃO}

Houve efeito significativo para genótipos $(\mathrm{G})$ em todas as variáveis avaliadas, indicando variabilidade genética que poderá ser explorada pela seleção (tabela I). Tal variabilidade foi possível devido aos cruzamentos entre os cultivares parentais que são altamente heterozigotos. Por outro lado, só houve efeito do fator nitrogênio (N) para a variável comprimento do entrenó. Para a interação tripla, não houve efeito para as variáveis altura da planta e diâmetro do colmo ( $p>0,05)$.

$\mathrm{Na}$ análise de adaptabilidade, observouse que os genótipos HV 241, Taiwan A-146, Elefante B e IRI 381, além de diferentes de 1 $(\mathrm{p}<0,05)$, foram adaptados a ambientes que favoreceram o maior potencial produtivo $\left(\beta_{1}>1\right)$, ou seja, aqueles com maior precipitação pluvial. Já o cultivar Mineirão, apesar de diferente de 1 , adaptou-se a ambientes desfavoráveis $\left(\beta_{1}<1 ; p<0,05\right)$, concordando com os resultados obtidos por Souto e Aronovich (1992), em que não houve resposta desse cultivar com a melhoria ambiental (adubação nitrogenada e irrigação). 
Tabela I. Resultado da ANOVA (testes $F$ ) das variáveis massa de forragem (MF), altura da planta $(A P)$, comprimento $(C F)$ e largura da folha $(L F)$, diâmetro do colmo $(D C)$ e comprimento do entrenó (CE) de genótipos de Pennisetum spp. sob quatro níveis de $N$, seis ciclos de avaliação e três blocos. (Result of ANOVA ( $\mathrm{F}$ test) of variables forage mass, plant height, leaf length, leaf width, stem diameter and internode length of Pennisetum spp. under four $\mathrm{N}$ levels, six evaluations cycles and three blocks).

\begin{tabular}{|c|c|c|c|c|c|c|}
\hline & \multicolumn{6}{|c|}{ ANOVA - Testes F } \\
\hline & MF & AP & CF & LF & DC & CE \\
\hline \multicolumn{7}{|l|}{ Fontes de variação } \\
\hline Blocos & 3,80 & 1,97 & 2,03 & 0,82 & 0,57 & 24,87 \\
\hline Genótipos (G) & $9,38^{* *}$ & $8,58^{* *}$ & $31,08^{* *}$ & $32,33^{\star *}$ & $18,08^{* *}$ & $33,32^{\star *}$ \\
\hline Nitrogênio (N) & $0,08 \mathrm{~ns}$ & $2,30 \mathrm{~ns}$ & $0,45 \mathrm{~ns}$ & $1,05 \mathrm{~ns}$ & $0,12 \mathrm{~ns}$ & $15,17^{\star \star}$ \\
\hline Ciclos $(\mathrm{Cl})$ & $94,21^{* *}$ & $200,93^{\star *}$ & $199,58^{* *}$ & $75,87^{\star *}$ & $119,26^{\star *}$ & $318,90^{* *}$ \\
\hline Interação G x N & $6,29^{* *}$ & $2,44^{* *}$ & $3,69^{* *}$ & $5,19^{* *}$ & $2,97^{* *}$ & $7,97^{\star *}$ \\
\hline Interação G x Cl & $1,72^{\star *}$ & $2,22^{\star *}$ & $5,21^{* *}$ & $2,95^{\star \star}$ & $3,89^{* *}$ & $4,65^{\star *}$ \\
\hline Interação N x Cl & $2,15^{\star *}$ & 2,05 ns & $1,81^{*}$ & $5,86^{\star *}$ & $2,38^{\star \star}$ & $7,96^{* *}$ \\
\hline Interação $\mathrm{G} \times \mathrm{N} \times \mathrm{Cl}$ & $1,39^{\star *}$ & $0,77 \mathrm{~ns}$ & $5,21^{\star *}$ & $1,70^{\star *}$ & $0,75 \mathrm{~ns}$ & $4,68^{\star *}$ \\
\hline
\end{tabular}

${ }^{*} \mathrm{p}<0,05 ;{ }^{*} \mathrm{p}<0,01 ; n s=$ não significativo pelo teste $\mathrm{F}$.

Esta adaptação a ambiente desfavorável pode está relacionada a uma maior profundidade do sistema radicular, associada a uma maior eficiência de absorção e de utilização dos nutrientes do solo, bem como uma maior eficiência no uso da água. Os demais genótipos, principalmente os novos híbridos, apresentaram adaptabilidade geral $\left(\beta_{1}=1\right)$, pois não diferiram de 1 (tabela II).

Todos os genótipos apresentaram alta estabilidade, com desvios de regressão não significativos $\left(\sigma_{\mathrm{di}}^{2}=0\right)$, ou seja, os genótipos apresentaram comportamento altamente previsível em função do estímulo ambiental (precipitação, principalmente). A massa de forragem do cultivar Taiwan A-146 apresentou alta estabilidade no experimento desenvolvido por Xavier et al. (1998) em Coronel Pacheco/MG, em quatro anos de avaliação, indicando que este cultivar apresentou variação mínima em seu fenótipo nos diferentes ambientes, fato observado nesta pesquisa.

Foram formados quatro grupos de similaridade pelo método de Tocher para a massa de forragem. O grupo I foi composto por nove dos 10 novos híbridos gerados (tabela III). Os genótipos que compuseram o grupo I nos ciclos 1, 3, 5 e 6 foram melhor ajustados por uma função quadrática, cujos pontos de produção máxima de forragem $\left(0,65 ; 0,54 ; 0,76\right.$ e $0,64 \mathrm{~kg}^{\mathrm{MS}}$ touceira ${ }^{-1}$ corte $\left.^{-1}\right)$, foram obtidos com as doses de 45,$57 ; 42,93 ; 45,56$ e $15,04 \mathrm{~kg} \mathrm{~N} \mathrm{ha}^{-1}$, respectivamente. Os coeficientes de determinação $\left(\mathrm{R}^{2}\right)$ foram de média-alta magnitude para todas as equações, apontando que os modelos foram ajustados satisfatoriamente, podendo explicar a maior parte da variação da massa de forragem dos genótipos avaliados por ciclo.

Nos ciclos 2 e 4 do grupo I, em todos os ciclos do grupo II e nos ciclos 1,3 e 5 do grupo IV, a função cúbica foi a que melhor se ajustou à variação dos tratamentos, com $\mathrm{R}^{2}$ de alta magnitude. Para os genótipos que formaram estes grupos, admitiu-se que estes podem está fixando $\mathrm{N}$ biologicamente, por meio da associação com bactérias diazotróficas. Considerando que o $\mathrm{N}$-inorgânico reduz a população desses organismos (Medeiros et al., 2006; Kraiser et al., 2011), 
Tabela II. Estimativas dos parâmetros de adaptabilidade e de estabilidade pelo método de Eberhart e Russell para massa de forragem de 16 genótipos de Pennisetum spp. avaliados por seis ciclos. (Estimates adaptability and stability parameters by Eberhart and Russell method to forage mass of 16 Pennisetum spp. genotypes evaluates in six cycles).

\begin{tabular}{lccc}
\hline Genótipos & $\beta_{0}$ & $\beta_{1}$ & $\sigma^{2}{ }_{\text {di }}$ \\
\hline Híbridos interespecíficos & & \\
IPA-1 & 0,66 & $1,13 \mathrm{~ns}$ & $-0,064 \mathrm{~ns}$ \\
IPA-7 & 0,88 & $0,79 \mathrm{~ns}$ & $-0,034 \mathrm{~ns}$ \\
IPA-8 & 0,64 & $0,82 \mathrm{~ns}$ & $-0,067 \mathrm{~ns}$ \\
IPA-A2 & 0,70 & $1,07 \mathrm{~ns}$ & $-0,066 \mathrm{~ns}$ \\
IPA-A4 & 0,67 & $1,02 \mathrm{~ns}$ & $0,034 \mathrm{~ns}$ \\
IPA-A5 & 0,58 & $0,74 \mathrm{~ns}$ & $-0,065 \mathrm{~ns}$ \\
IPA-B1 & 0,69 & $0,65 \mathrm{~ns}$ & $-0,064 \mathrm{~ns}$ \\
IPA-B3 & 0,58 & $0,72 \mathrm{~ns}$ & $-0,067 \mathrm{~ns}$ \\
IPA-C8 & 0,55 & $0,86 \mathrm{~ns}$ & $-0,056 \mathrm{~ns}$ \\
IPA-C9 & 0,56 & $0,88 \mathrm{~ns}$ & $-0,064 \mathrm{~ns}$ \\
HV 241 & 1,45 & $1,30^{*}$ & $0,004 \mathrm{~ns}$ \\
Cultivares & & & \\
Mineirão & 1,16 & $0,48^{*}$ & $-0,043 \mathrm{~ns}$ \\
Taiwan A-146 & 1,47 & $1,28^{*}$ & $-0,061 \mathrm{~ns}$ \\
Elefante B & 1,46 & $1,78^{*}$ & $-0,066 \mathrm{~ns}$ \\
IRI381 & 1,06 & $1,41^{*}$ & $-0,057 \mathrm{~ns}$ \\
Pioneiro & 0,84 & $1,07 \mathrm{~ns}$ & $-0,039 \mathrm{~ns}$ \\
\hline
\end{tabular}

ns: não significativo a $5 \%$ de probabilidade. ${ }^{*} \beta_{1}$ diferente de 1 pelo teste $t(p<0,05)$.

com a fertilização de $30 \mathrm{~kg} \mathrm{~N} \mathrm{ha}^{-1}$ corte $^{-1}$, a população de bactérias diazotróficas poderia ter sido reduzida e a concentração de $\mathrm{N}$ existente na rizosfera pode não ter atendido a demanda das plantas, devido a possíveis perdas por processos como a lixiviação, a volatilização e/ou imobilização pela biota do solo. Por outro lado, com a aplicação de $60 \mathrm{~kg} \mathrm{~N} \mathrm{ha}^{-1}$ corte $^{-1}$, as plantas aumentaram a massa de forragem pelo maior aporte de $\mathrm{N}$ na rizosfera. Porém, quando adubado com $90 \mathrm{~kg} \mathrm{~N} \mathrm{ha}^{-1}$ corte $^{-1}$, a produção foi reduzida, provavelmente pelo efeito fitotóxico sobre o sistema radicular, como observado por Cruz et al. (2010), em que houve redução do $\mathrm{pH}$ de um Argissolo, chegando a $3,46 \mathrm{com} 90 \mathrm{~kg} \mathrm{~N} \mathrm{ha-1}$. Isto porque a hidrólise da uréia libera prótons $\mathrm{H}^{+}$, aumentando a acidez do solo (Lopez et al., 1991). Estas hipóteses poderiam explicar o efeito cúbico obtido nesta pesquisa. A variação da massa de forragem dentro de cada tratamento, devido as diferentes idades ontogenéticas, também poderia explicar o efeito cúbico observado para os genótipos. As variações da precipitação pluvial entre os ciclos também podem ter influenciado este fenômeno.

O novo híbrido IPA-7 e o seu progenitor masculino, o cultivar Pioneiro, que formaram o grupo III, não foram influenciados pelos níveis de $\mathrm{N}$ em nenhum dos ciclos, estimando-se a produtividade média em torno de 4,4 $\mathrm{Mg} \mathrm{MS} \mathrm{ha}^{-1}$ corte $^{-1}$. Esses genótipos também podem estar associados (Azospirilum spp. e Gluconacetobacter diazotrophicus) à capacidade de fixar $\mathrm{N}$ biologicamente, como observado por Silva et al. (2010), em genótipos de capim-elefante, em Itambé/PE, sob altura de corte de até $25,0 \mathrm{~cm}$, sem adubação nitrogenada. A influência do Nfertilizante sobre o incremento produtivo de várias culturas já foi bastante documentado na literatura. Em Pennisetum spp., esta ausência de resposta diverge das encontradas por diferentes autores, como Pegoraro et al. (2009) e Cruz et al. (2010) nos cultivares Napier e Cameroon, respectivamente, cujo efeito observado foi o linear em até $150 \mathrm{~kg}$ $\mathrm{N} \mathrm{ha}^{-1}$. Sendo assim, o novo híbrido IPA-7 poderia ser selecionado para ser utilizado em regiões de baixa tecnologia de produção, em que se predomina o baixo uso de $\mathrm{N}$ fertilizante pelos pecuaristas, desde que as características ambientais sejam semelhantes às de Itambé/PE.

Os grupos II e III foram formados por um híbrido cada. No desdobramento da interação genótipo x nitrogênio (figura 2), a altura dos genótipos do grupo I e III ajustaram-se a uma função cúbica, com início descendente, cujos pontos de máxima foram 1,54 e 2,06 m com as doses de 75 e $73 \mathrm{~kg} \mathrm{~N}$ ha $^{-1}$ corte $^{-1}$, respectivamente. Este efeito 
POTENCIAL PRODUTIVO DE PENNISETUM SPP. SOB NÍVEIS DE NITROGÊNIO

Tabela III. Agrupamento de Tocher e desdobramento da interação tripla para a massa de forragem ( $\mathrm{kg} \mathrm{MS}$ touceira $^{-1}$ corte $^{-1}$ ). (Tocher' cluster and triple interaction decomposition to forage mass (kg DM shoot $\left.{ }^{-1} \mathrm{cut}^{-1}\right)$ ).

\begin{tabular}{lll}
\hline Ciclos & Equações & $R^{2}$ \\
\hline Grupo I (IPA-1, IPA-8, IPA-A2, IPA-A4, IPA-A5, IPA-B1, IPA-B3, IPA-C8, IPA-C9) & \\
1 & $\mathrm{Y}=0,50054+0,00638 \mathrm{~N}-0,00007 \mathrm{~N}^{2}$ & 0,63 \\
2 & $\mathrm{Y}=0,81185-0,02901 \mathrm{~N}+0,00091 \mathrm{~N}^{2}-0,000007 \mathrm{~N}^{3}$ & 0,99 \\
3 & $\mathrm{Y}=0,37824+0,00747 \mathrm{~N}-0,000087 \mathrm{~N}^{2}$ & 0,83 \\
4 & $\mathrm{Y}=0,44667-0,01225 \mathrm{~N}+0,00034 \mathrm{~N}^{2}-0,0000024 \mathrm{~N}^{3}$ & 0,99 \\
5 & $\mathrm{Y}=0,55474+0,00902 \mathrm{~N}-0,000099 \mathrm{~N}^{2}$ & 0,65 \\
6 & $\mathrm{Y}=0,91037-0,03472 \mathrm{~N}+0,001154 \mathrm{~N}^{2}$ & 0,99 \\
Grupo II (HV 241, Taiwan A-146, Elefante $\mathrm{B})$ & \\
1 & $\mathrm{Y}=1,12889+0,05322 \mathrm{~N}-0,00148 \mathrm{~N}^{2}+0,000011 \mathrm{~N}^{3}$ & 0,99 \\
2 & $\mathrm{Y}=1,34667+0,07475 \mathrm{~N}-0,00247 \mathrm{~N}^{2}+0,000019 \mathrm{~N}^{3}$ & 0,99 \\
3 & $\mathrm{Y}=0,84889+0,05042 \mathrm{~N}-0,00129 \mathrm{~N}^{2}+0,000009 \mathrm{~N}^{3}$ & 0,99 \\
4 & $\mathrm{Y}=0,74222+0,04436 \mathrm{~N}-0,001489 \mathrm{~N}^{2}+0,000011 \mathrm{~N}^{3}$ & 0,99 \\
5 & $\mathrm{Y}=1,26444+0,06111 \mathrm{~N}-0,001627 \mathrm{~N}^{2}+0,000012 \mathrm{~N}^{3}$ & 0,99 \\
6 & $\mathrm{Y}=1,50667+0,08710 \mathrm{~N}-0,00279 \mathrm{~N}^{2}+0,000021 \mathrm{~N}^{3}$ & 0,99 \\
Grupo III (IPA-7, Pioneiro) & & \\
1 & $\mathrm{Y}=0,86(\mathrm{p}>0,05)$ & - \\
2 & $\mathrm{Y}=0,89(\mathrm{p}>0,05)$ & - \\
3 & $\mathrm{Y}=0,65(\mathrm{p}>0,05)$ & - \\
4 & $\mathrm{Y}=0,45(\mathrm{p}>0,05)$ & - \\
5 & $\mathrm{Y}=0,99(\mathrm{p}>0,05)$ & - \\
6 & $\mathrm{Y}=1,03(\mathrm{p}>0,05)$ & - \\
Grupo IV (Mineirão, IRI 381) & & \\
1 & $\mathrm{Y}=0,895+0,055898 \mathrm{~N}-0,001621 \mathrm{~N}^{2}+0,000012 \mathrm{~N}^{3}$ & 0,99 \\
2 & $\mathrm{Y}=1,4161667-0,0043222 \mathrm{~N}$ & 0,55 \\
3 & $\mathrm{Y}=0,67167-0,047843 \mathrm{~N}-0,00124 \mathrm{~N}^{2}+0,000083 \mathrm{~N}^{3}$ & 0,99 \\
4 & $\mathrm{Y}=0,784167-0,00375 \mathrm{~N}$ & 0,93 \\
5 & $\mathrm{Y}=1,00167-0,06436 \mathrm{~N}-0,00181 \mathrm{~N}^{2}+0,000013 \mathrm{~N}^{3}$ & 0,99 \\
6 & $\mathrm{Y}=1,575-0,02921296 \mathrm{~N}$ & 0,99 \\
\hline & &
\end{tabular}

pode está associado à influência do N-fertilizante sobre a redução da população de bactérias diazotróficas. Por outro lado, o genótipo do grupo II, o híbrido IPA-A2, ajustou-se a uma função linear. Também em um Argissolo, Cruz et al. (2010) observaram efeito quadrático, com altura máxima de 3,22 m para o cultivar de capim-elefante Cameroon na dose de $100 \mathrm{~kg} \mathrm{~N} \mathrm{ha}^{-1}$, onde a colheita ocorreu aos 150 dias após o plantio. Os diferentes comportamentos dos genótipos frente as doses de $\mathrm{N}$ observados nesses resultados podem estar relacionadas com a variação genética (cultivares e híbridos).

Para o comprimento da folha, houve a formação de três grupos pelo método de Tocher (tabela IV). Os genótipos que formaram o grupo I, no ciclo 3, apresentaram resposta linear com os níveis de N, ou seja, para cada unidade de $\mathrm{N}$ aplicado houve incremento no comprimento da folha de $0,0684 \mathrm{~cm}$. Nos demais grupos de similaridade genética e ciclos de avaliação, não houve resposta da adubação nitrogenada sobre os genótipos $(\mathrm{p}>0,05)$. Isto pode estar associado à baixa susceptibilidade ambiental que este caráter apresenta, uma vez que o componente genético pode ser explicado por até $93 \%$, através de seu coeficiente de herdabilidade, como observado por Silva et 


\section{CAVALCANTE, LIRA, SANTOS, SANTORO, FERREIRA E LEÃONETO}

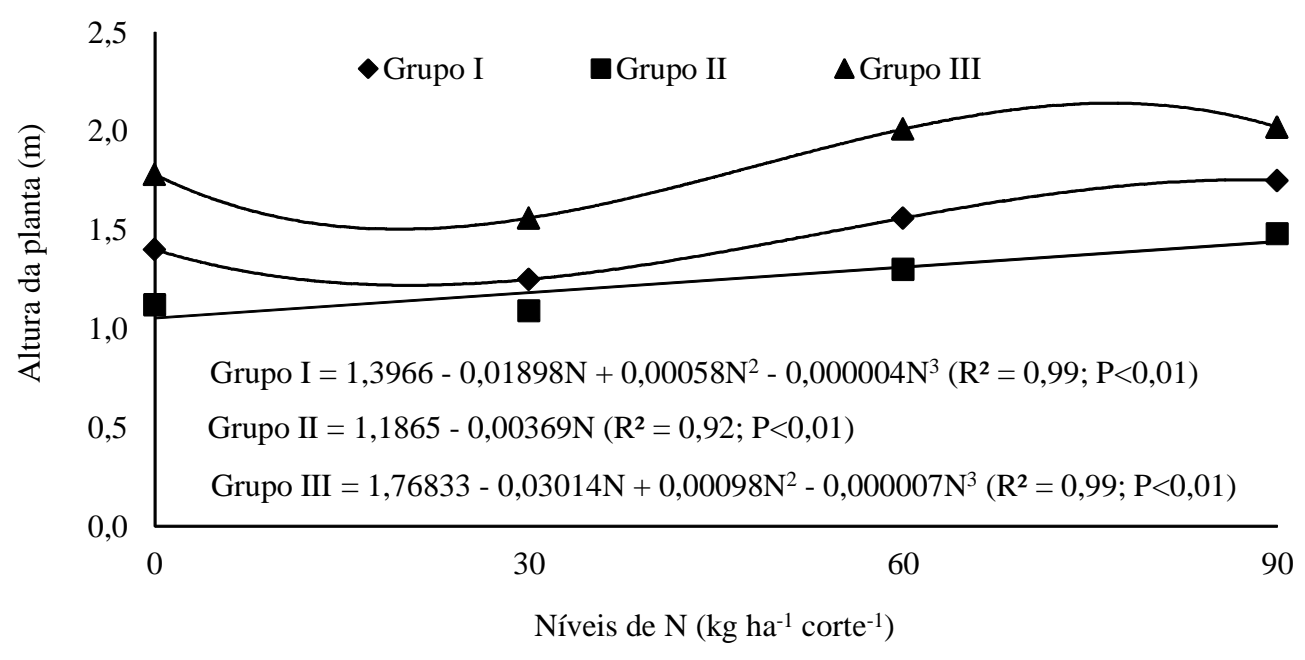

Figura 2. Desdobramento da interação genótipo x nitrogênio para a altura da planta $(m)$. Grupo I: IPA-1, IPA-7, IPA-8, IPA-A4, IPA-A5, IPA-B1, IPA-B3, IPA-C8, IPA-C9, Mineirão, Taiwan A-146, Elefante B, IRI 381, Pioneiro; Grupo II: IPA-A2; Grupo III: HV241. Média de seis ciclos de avaliações. (Genotype $\mathrm{x}$ nitrogen interaction deployment to plant height $(\mathrm{m})$. Cluster $\mathrm{I}$ : IPA-1, IPA-7, IPA-8, IPA-A4, IPA-A5, IPA-B1, IPA-B3, IPA-C8, IPA-C9, Mineirão, Taiwan A-146, Elefante B, IRI 381, Pioneiro; Cluster II: IPA-A2; Cluster III: HV 241. Average of six evaluations cycles).

al. (2009), em nove genótipos de capimelefante. Esta ausência de resposta é uma característica de interesse, uma vez que as folhas, além de serem o principal órgão da planta responsável pelas reações de fixação de $\mathrm{CO}_{2}$ (Taiz e Zeiger, 2006) e pela formação dos carboidratos de reserva (Cecato et al., 2001), consistem na fração mais digestível da planta, chegando a digestibilidade de 63 \% (Silva et al., 2011), sendo responsáveis pela maior parte da nutrição dos ruminantes.

Para largura da folha, houve a formação de dois grupos de similaridade, sendo o primeiro composto por 15 genótipos (tabela V). O grupo II foi formado pelo híbrido interespecífico HV 241. Este híbrido apresentou resposta quadrática no $2^{\circ}$ e no $6^{\circ}$ ciclo, com largura máxima de 44,92 e de 48,88 mm para os níveis 49,09 e 49,25 $\mathrm{kg} \mathrm{N} \mathrm{ha}^{-1}$ corte $^{-1}$, respectivamente. Apesar de os genótipos que formaram o grupo I terem apresentado efeito quadrático, quando aplicado $30 \mathrm{~kg} \mathrm{~N} \mathrm{ha}^{-1}$ corte $^{-1}$, houve redução da largura foliar, tanto no $2^{\circ}$ quanto no $6^{\circ}$ ciclo, sendo os pontos de mínima, respectivamente, de 22,80 e 24,84 $\mathrm{mm}$ com as doses de 37,84 e $37,68 \mathrm{~kg} \mathrm{~N}$ corte $^{-1}$. Este evento pode estar relacionado ao efeito negativo do $\mathrm{N}$-fertilizante sobre a população bacteriana fixadora de $\mathrm{N}_{2}$, bem como a baixa concentração de $\mathrm{N}$ na rizosfera.

O diâmetro do colmo apresentou dois grupos de similaridade (tabela V), com a mesma formação observada para a largura da folha (tabela V). Os genótipos do grupo I apresentaram resposta cúbica no ciclo 4 . A precipitação observada após a $3^{\mathrm{a}}$ avaliação (28/09/2010) foi de 53,1 mm em outubro, 3,5 $\mathrm{mm}$ em novembro, $10,9 \mathrm{~mm}$ em dezembro e 30,1 mm entre 01 a 06/01/2011, ocasião da $4^{\mathrm{a}}$ avaliação. Sendo assim, o efeito cúbico observado nos genótipos do grupo I no $4^{\circ}$ ciclo pode ter sido influenciado por estas variações da precipitação pluvial. Por outro lado, o híbrido HV 241 (grupo II) apresentou função quadrática, com diâmetro máximo 


\section{POTENCIAL PRODUTIVO DE PENNISETUM SPP. SOB NÍVEIS DE NITROGÊNIO}

$(12,58 \mathrm{~mm})$ na dose de $52,83 \mathrm{~kg} \mathrm{Nha}^{-1}$ corte $^{-1}$. Este efeito pode ter sido devido ao aumento em altura da planta (alongamento do caule) que ocorreu entre os níveis 30 e $60 \mathrm{~kg} \mathrm{~N} \mathrm{ha}^{-1}$ corte $^{-1}$ (figura 2, grupo III).

O comprimento do entrenó foi a variável que apresentou maior variabilidade entre os genótipos, promovendo a formação de cinco grupos de similaridade (tabela VI). Para os genótipos do grupo I, os ciclos 1,3 e 4 apresentaram função linear com o incremento da fertilização nitrogenada. Por outro lado, os genótipos do grupo II, dentre eles os novos híbridos IPA-7 e o IPA-C8, não sofreram influência do $\mathrm{N}$-fertilizante em nenhum dos ciclos de avaliação, sendo classificados como adaptados e estáveis

Tabela IV. Agrupamento de Tocher e desdobramento da interação tripla para o comprimento da folha $(\mathrm{cm})$. (Tocher' cluster and triple interaction decomposition to leaf length $(\mathrm{cm})$ ).

\begin{tabular}{|c|c|c|}
\hline Ciclos & Equações & $\mathrm{R}^{2}$ \\
\hline \multicolumn{3}{|c|}{$\begin{array}{l}\text { Grupo I (IPA-1, IPA-8, IPA-A2, IPA-A4, IPA-A5, } \\
\text { IPA-B1, IPA-B3, IPA-C8, IPA-C9) }\end{array}$} \\
\hline 1 & $Y=68,60(p>0,05)$ & - \\
\hline 2 & $Y=53,77(p>0,05)$ & - \\
\hline 3 & $Y=55,570307+0,068395 N$ & 0,76 \\
\hline 4 & $Y=55,02(p>0,05)$ & - \\
\hline 5 & $Y=82,32(p>0,05)$ & - \\
\hline 6 & $Y=65,18(p>0,05)$ & \\
\hline \multirow{2}{*}{\multicolumn{3}{|c|}{$\begin{array}{l}\text { Grupo II (IPA-7, Mineirão, Taiwan A-146, Elefante } \\
\text { B, IRI 381, Pioneiro) }\end{array}$}} \\
\hline & & \\
\hline 1 & $Y=84,09(p>0,05)$ & - \\
\hline 2 & $Y=73,93(p>0,05)$ & - \\
\hline 3 & $Y=72,17(p>0,05)$ & - \\
\hline 4 & $Y=79,11(p>0,05)$ & - \\
\hline 5 & $Y=100,87(p>0,05)$ & - \\
\hline 6 & $Y=89,56 \quad(p>0,05)$ & - \\
\hline \multicolumn{3}{|c|}{ Grupo III (HV 241) } \\
\hline 1 & $Y=111,83(p>0,05)$ & - \\
\hline 2 & $Y=97,58 \quad(p>0,05)$ & - \\
\hline 3 & $Y=96,17(p>0,05)$ & - \\
\hline 4 & $Y=80,33(p>0,05)$ & - \\
\hline 5 & $Y=134,25(p>0,05)$ & - \\
\hline 6 & $Y=118,33(p>0,05)$ & - \\
\hline
\end{tabular}

Tabela V. Agrupamento de Tocher e desdobramento da interação tripla para a largura da folha e diâmetro do colmo. (Tocher' cluster and triple interaction decomposition to leaf width and stem diameter).

Ciclos Equações (largura da folha, $\mathrm{mm}$ ) $\quad \mathrm{R}^{2}$ Grupo ${ }^{*}$

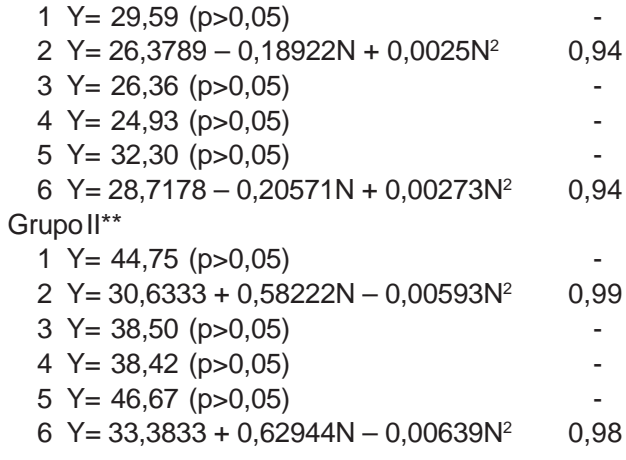

Ciclos Equações (diâmetro do colmo, mm) $\quad \mathrm{R}^{2}$ Grupo I*

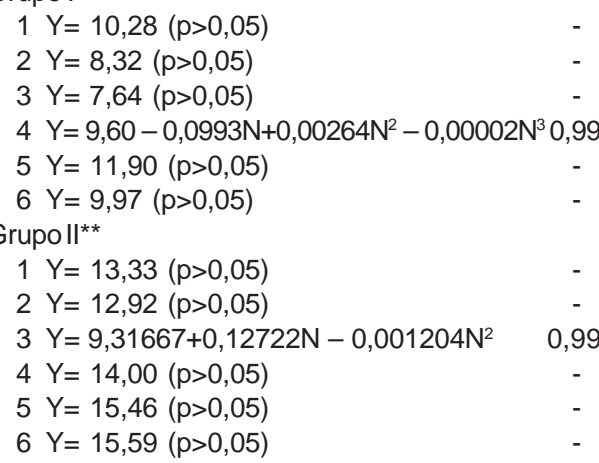

*IPA-1, IPA-7, IPA-8, IPA-A2, IPA-A4, IPA-A5, IPAB1, IPA-B3, IPA-C8, IPA-C9, Mineirão, Taiwan A146, Elefante B, IRI 381, Pioneiro. **HV 241.

geneticamente (Cruz e Regazzi, 2001). Já os genótipos do grupo III (IPA-A2, IPA-C9 e Pioneiro) apresentaram resposta quadrática nos ciclos 2, 3, 4 e 6 com o incremento dos níveis de $\mathrm{N}$. Os comprimentos máximos $(64,15 ; 62,94 ; 96,52$ e $70,15 \mathrm{~mm}$, respectivamente) foram obtidos com as doses 42,60 ; 59,$48 ; 57,56$ e $41,83 \mathrm{~kg} \mathrm{~N} \mathrm{ha}^{-1}$ corte $^{-1}$, respec- 


\section{CAVALCANTE, LIRA, SANTOS, SANTORO, FERREIRA E LEÃO NETO}

Tabela VI. Agrupamento de Tocher e desdobramento da interação tripla para o comprimento do entrenó $(\mathrm{mm})$. (Tocher' cluster and triple interaction decomposition to internode length $(\mathrm{mm})$ ).

\begin{tabular}{|c|c|c|}
\hline Ciclos & Equações & $\mathrm{R}^{2}$ \\
\hline \multicolumn{3}{|c|}{ Grupo I (IPA-A4, IPA-A5, IPA-B1, IPA-B3, Mineirão, Taiwan A-146) } \\
\hline 1 & $Y=72,28889+0,08926 \mathrm{~N}$ & 0,77 \\
\hline 2 & $Y=86,88(p>0,05)$ & - \\
\hline 3 & $Y=63,16889+0,10526 \mathrm{~N}$ & 0,94 \\
\hline 4 & $Y=89,42778+0,23000 \mathrm{~N}$ & 0,95 \\
\hline 5 & $Y=83,14(p>0,05)$ & - \\
\hline 6 & $Y=92,38(p>0,05)$ & - \\
\hline \multicolumn{3}{|c|}{ Grupo II (IPA-7, IPA-C8, HV-241, Elefante B) } \\
\hline 1 & $Y=69,50(p>0,05)$ & - \\
\hline 2 & $Y=79,02(p>0,05)$ & - \\
\hline 3 & $Y=60,25(p>0,05)$ & - \\
\hline 4 & $Y=98,56(p>0,05)$ & - \\
\hline 5 & $Y=72,83(p>0,05)$ & - \\
\hline 6 & $Y=84,02(p>0,05)$ & - \\
\hline \multicolumn{3}{|c|}{ Grupo III (IPA-A2, IPA-C9, Pioneiro) } \\
\hline 1 & $Y=72,28889+0,08926 \mathrm{~N}$ & 0,77 \\
\hline 2 & $Y=79,61111-0,72593 N+0,00852 N^{2}$ & 0,88 \\
\hline 3 & $\mathrm{Y}=46,62889+0,54837 \mathrm{~N}-0,00461 \mathrm{~N}^{2}$ & 0,92 \\
\hline 4 & $Y=67,5944+1,005 \mathrm{~N}-0,00873 \mathrm{~N}^{2}$ & 0,98 \\
\hline 5 & $Y=62,96667+0,08963 \mathrm{~N}$ & 0,73 \\
\hline 6 & $Y=83,87778-0,65593 N+0,00784 N^{2}$ & 0,96 \\
\hline \multicolumn{3}{|c|}{ Grupo IV (IPA-1, IRI 381) } \\
\hline 1 & $Y=81,58(p>0,05)$ & - \\
\hline 2 & $\mathrm{Y}=77-1,51574 \mathrm{~N}+0,07343 \mathrm{~N}^{2}-0,00059 \mathrm{~N}^{3}$ & 0,99 \\
\hline 3 & $Y=70,83(p>0,05)$ & - \\
\hline 4 & $Y=87,6667+1,2287 N-0,0360 N^{2}+0,0003 N^{3}$ & 0,99 \\
\hline 5 & $Y=87,29(p>0,05)$ & - \\
\hline 6 & $\mathrm{Y}=82,6667-1,7240 \mathrm{~N}+0,082 \mathrm{~N}^{2}-0,0007 \mathrm{~N}^{3}$ & 0,99 \\
\hline \multicolumn{3}{|c|}{ Grupo V (IPA-8) } \\
\hline 1 & $Y=84,17(p>0,05)$ & - \\
\hline 2 & $Y=72,933333+4,25556 \mathrm{~N}$ & 0,93 \\
\hline 3 & $Y=77,25(p>0,05)$ & - \\
\hline 4 & $Y=82,36667+10,100 N$ & 0,92 \\
\hline 5 & $Y=90,17(p>0,05)$ & - \\
\hline 6 & $Y=80,16667+6,5889 \mathrm{~N}$ & 0,84 \\
\hline
\end{tabular}

tivamente. É possível que a umidade acumulada do solo nos ciclos 2 e 6 favoreceu a lixiviação do $\mathrm{N}$-fertilizante na dose de $30 \mathrm{~kg}$ $\mathrm{N} \mathrm{ha}^{-1}$ corte $^{-1}$, explicando assim, a redução no comprimento do entrenó. O grupo $\mathrm{V}$, formado pelo híbrido IPA-8, apresentou resposta linear com o incremento dos níveis de $\mathrm{N}$ nos ciclos 2,4 e 6 .

Apesar de os novos híbridos (IPA-1,
IPA-8, IPA-A2, IPA-A4, IPA-A5, IPA-B1, IPA-B3, IPA-C8, IPA-C9) apresentarem como progenitor masculino variedades distintas, estes tiveram alta similaridade genética pelo método de Tocher, formando um mesmo agrupamento nas variáveis massa de forragem, comprimento e largura da folha e diâmetro do colmo. É possível que o componente genético do progenitor feminino 


\section{POTENCIAL PRODUTIVO DE PENNISETUM SPP. SOB NÍVEIS DE NITROGÊNIO}

(cultivar IPA Bulk-1) tenha influenciado estas características.

\section{CONCLUSÕES}

O fator ambiental, representado pelos níveis de nitrogênio e pelos ciclos de avaliação que ocorreram ao longo do período experimental, exerce influência sobre as variáveis agronômicas dos genótipos avaliados.

\section{BIBLIOGRAFIA}

Beltrão, B.A.; Mascarenhas, G.C.; Miranda, J.L.F.; Souza Júnior, L.C.; Galvão, M.J. da T.G. e Pereira, S.N. 2005. Projeto cadastro de fontes de abastecimento por água subterrânea Estado de Pernambuco: diagnóstico do município de Itambé. CPRM/PRODEEM. Recife. 22 pp.

Carneiro, M.S. de S.; Souza, P.Z.; Peixoto, M.J.A.; Sales, S. de O. e Feitosa, J.V. 2006. Efeito do consórcio de capim-elefante com leucena na produção de forragem. Rev Caatinga, 19: 5155.

Cecato, U.; Cano, C.C.P.; Bortolo, M.; Herling, V.R.; Canto, M.W. do e Castro, C.R. de C. 2001. Teores de carboidratos não-estruturais, nitrogênio total e peso de raízes em Coastcross1 [Cynodon dactylon (L.) Pers] pastejado por ovinos. Rev Bras Zootecn, 43: 1637-1639.

Cruz, R.S. da; Santos, A.C. dos; Castro, J.G.D.; Alexandrino, E.; Caraça, D.C. e Diniz, J.P. 2010. Produtividade do Capim-Cameroon estabelecida em duas classes de solos e submetido a doses crescentes de nitrogênio no norte tocantinense. Acta Sci Anim Sci, 32: 393-399.

Cruz, C.D. 2006. Programa Genes: estatística experimental e matrizes. UFV. Viçosa. $285 \mathrm{pp}$.

Cruz, C.D. e Regazzi, A.J. 2001. Modelos biométricos aplicados ao melhoramento genético. $2^{\mathrm{a}}$ ed. UFV. Viçosa. $390 \mathrm{pp}$.

Ferreira, R.P. e Pereira, A.V. 2005. Melhoramento de forrageiras. Em: Borém, A. (Ed.). Melhoramento de espécies cultivadas. UFV. Viçosa. pp. 781-812.

Freitas, E.V. de; Lira, M. de A.; Dubeux Júnior, J.C.B.; Santos, M.V.F. dos; Mello, A.C.L. de; Tabosa, J.N. e Farias, I. 2004. Características
O novo híbrido IPA-7 (Pioneiro x IPA Bulk-1) não é influenciado pelos níveis de $\mathrm{N}$ dentro de cada ciclo de avaliação quanto as variáveis massa de forragem, comprimento da folha e comprimento do entrenó. Apresenta adaptabilidade geral e alta estabilidade, sendo indicado para ser usado nas próximas fases do Programa de Melhoramento do Capim-Elefante e de seus Híbridos com Milheto na Zona da Mata de Pernambuco.

produtivas e qualitativas de clones de capimelefante (Pennisetum purpureum Schum.) avaliados sob pastejo na zona da mata de Pernambuco. Acta Sci Anim Sci, 26: 251-257. Jauhar, P.P. and Hanna, W.W. 1998. Cytogenetics and genetics of pearl millet. Adv Agron, 64: 1-26.

Kraiser, T.; Gras, D.E.; Gutiérrez, A.G.; González, B. and Gutiérrez, R. 2011. A holistic view of nitrogen acquisition in plants. J Exp Bot, 62: 1455-1466.

Lira, M. de A. 1982. Cultura do milheto. Cultura do milheto: curso para extensionista agrícola. Empresa Pernambucana de Pesquisa Agropecuária. BNB-ETENE. Fortaleza. pp. 9-22.

Lira, M. de A.; Cunha, M.V. da e Pereira, A.V. 2010. Melhoramento genético do capim-elefante. Em: L.M. de A.; Santos, M.V.F. dos; Dubeux Júnior, J.C.B. e Mello, A.C.L. de (Eds.). Capim-elefante: fundamentos e perspectivas. IPA/UFRPE. Recife. pp. 31-48.

Lira, M. de A.; Farias, I.; Ferdandes, A.P.M.; Soares, L.M. e Dubeux Júnior, J.C.B. 1996. Efeito da adubação nitrogenada e fosfatada no rendimento do capim-elefante (Pennisetum purpureum Schum.). Pesqui Agropecu Bras, 31: 19-26.

Lopez, A.S.; Silva, M.C. e Guilherme, L.R.G. 1991. Acidez do solo e calagem. ANDA. São Paulo. 17 pp.

Medeiros, A.F.A.; Polidoro, J.C. and Reis, V.M. 2006. Nitrogen source effect on Gluconacetobacter diazotrophicus colonization of sugarcane (Saccharum spp.). Plant Soil, 279: 141-152.

Pegoraro, R.F.; Mistura, C.; Wendling, B.; Fonseca, D.M. da e Fagundes, J.L. 2009. Manejo da água

Archivos de zootecnia vol. 62, núm. 240, p. 511. 


\section{CAVALCANTE, LIRA, SANTOS, SANTORO, FERREIRA E LEÃONETO}

e do nitrogênio em cultivo de capim-elefante. Ciênc Agrotec, 33: 461-467.

Pereira, A.V.; Martins, C.E.; Cruz Filho, A.B.; Cóser, A.C.; Teles, F.M.; Ferreira, R.P.; Amorim, M.E.T. e Rocha, A.F. 1997. Pioneiro: nova cultivar de capim-elefante para pastejo. Em: Reunião Anual da Sociedade Brasileira de Zootecnia, 34. Anais... SBZ. Juiz de Fora. pp. 102-104.

Primavesi, A.C.; Primavesi, O.; Corrêa, L. de A.; Cantarella, H.; Silva, A.G. da; Freitas, A.R. de e Vivaldi, L.J. 2004. Adubação nitrogenada em capim-coastcross: efeitos na extração de nutrientes e recuperação aparente do nitrogênio. Rev Bras Zootecn, 33: 68-78.

Santos, D.C. dos; Lira, M. de A. e Dubeaux Júnior, J.C.B. 2008. Capineira de Pennisetum purpureumSchum. Em: Cavalcanti, F.J.A. (Ed.). Recomendação de adubação para o Estado de Pernambuco: 2 ${ }^{\underline{a}}$ aproximação. $3^{\underline{a}}$ ed. rev. IPA, Recife. pp. 136.

SAS Institute Inc. 2008. SAS/STAT 9.2: User's guide for Mixed procedure. SAS Institute Inc, Cary. 224 pp.

Silva, A.L.C. da; Santos, M.V.F. dos; Ferreira, R.L.C.; Dubeux Júnior, J.C.B.; Lira, M. de A.; Cunha, M.V. da; Pereira, A.V. e Araújo, G.G.L. de. 2011. Variabilidade e herdabilidade de ca- racteres qualitativos relacionados à qualidade de forragem de clones de capim-elefante na Zona da Mata de Pernambuco. Rev Bras Zootecn, 40: 39-46.

Silva, L.L.G.G. da; Alves, G.C.; Ribeiro, J.R.A.; Urquiaga, S.; Souto, S.M.; Figueiredo, M.V.B. e Burity, H.A. 2010. Fixação biológica de nitrogênio em pastagens com diferentes intensidades de corte. Arch Zootec, 59: 21-30.

Silva, S.H.B. da; Santos, M.V.F. dos; Lira, M. de A.; Dubeux Júnior, J.C.B.; Freitas, E.V. de e Ferreira, R.L.C. 2009. Uso de descritores morfológicos e herdabilidade de caracteres em clones de capimelefante de porte baixo. Rev Bras Zootecn, 38: 1451-1459.

Souto, S.M. e Aronovich, S. 1992. Tolerância à seca em forrageiras tropicais: aspectos agronômicos e microbiológicos. Embrapa/ CNPBS. Seropédica. 28 pp.

Taiz, L. and Zeiger, E. 2006. Plant physiology. $4^{\text {a }}$ ed. Sinauer Associates. Massachusetts. 764 pp.

Xavier, D.F.; Botrel, M.A.; Verneque, R.S.; Freitas, V.P. e Boddey, R.M. 1998. Estabilidade da produção de forragem de cultivares de capimelefante em solo com baixa disponibilidade de nitrogênio. Rev Past Tropic, 20: 35-40. 